\title{
Giant Cell Tumor of the Skull: Review of the Literature
}

\author{
Ryota Tamura ${ }^{1}$ Tomoru Miwa ${ }^{1}$ Kazuhiko Shimizu ${ }^{2}$ Katsuhiro Mizutani ${ }^{1}$ Hideyuki Tomita ${ }^{1}$ \\ Nobuo Yamane ${ }^{3}$ Takehiro Tominaga $^{4}$ Shunichi Sasaki ${ }^{4}$
}

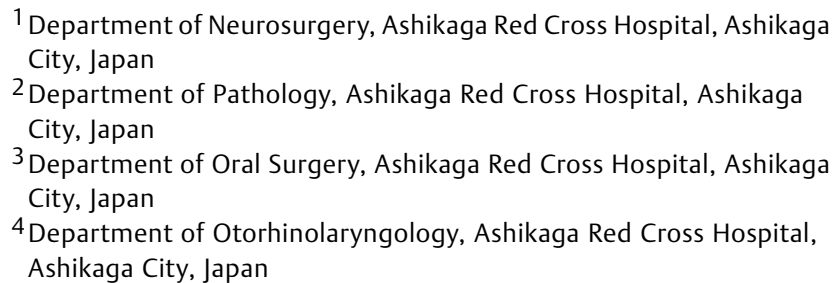

Address for correspondence Ryota Tamura, MD, Department of Neurosurgery, Ashikaga Red Cross Hospital, 284-1 Yobe-cho, Ashikaga City 326-0843, Japan (e-mail: moltobello-r-610@hotmail.co.jp).

J Neurol Surg A 2016;77:239-246.

\begin{abstract}
Keywords

- giant cell tumor

- bisphosphonate

- RANKL

- denosumab

- temporal bone

Background Giant cell tumors (GCTs) are rare in the skull. The present report describes a case with a primary GCT located in the temporal bone and reviews the relevant literature. We also propose a treatment strategy for GCT of the skull.

Clinical Presentation A 41-year-old man presented with headache and auditory disturbance. Radiologic images showed a lytic expansive extradural lesion originating primarily from the right temporal bone and expanding into the middle cranial fossa and the infratemporal fossa. A biopsy specimen of the lesion was obtained from the external auditory meatus. Total removal was performed with temporal craniectomy, mandibular condylar process removal, tympanoplasty, and mastoidectomy.

Discussion The rate of recurrence of GCTs is related to complete resection and location of the GCT rather than to the degree of invasiveness. Some of the mononuclear cells and stromal cells in GCT express receptor activator of nuclear factor $\mathrm{k}-\beta$ ligand (RANKL). Because inhibition of RANKL and bisphosphonate therapy might eliminate giant cells, this approach might be useful for recurrent or unresectable GCTs of the skull. Conclusions Preoperative diagnosis by biopsy is important in determining the therapeutic strategy of GCTs. Complete resection is important to reduce the recurrence rate of GCTs in the skull.
\end{abstract}

\section{Introduction}

Giant cell tumors (GCTs) mainly originate in the metaphyseal region of the long bones, especially in the distal femur, proximal tibia, and distal radius. GCTs are rare primary bone neoplasms, representing only $5 \%$ of all bone tumors, and they are exceedingly rare in the skull. ${ }^{1-11} \mathrm{GCT}$ in the skull was first reported by Echols in $1945,{ }^{12}$ and more than a dozen cases have since been described. GCTs of the skull occur most frequently in the sphenoid and temporal bones and very rarely in the frontal, parietal, and occipital bones. ${ }^{4,6}$

Although GCTs in the skull are characterized as benign, they can be locally aggressive and biologically unpredictable. Total surgical removal is frequently difficult, and the use of both adjuvant radiotherapy and chemotherapy remains controversial. Recent reports suggest that monoclonal antibodybased treatment and bisphosphonate may be useful for the treatment of GCTs of the long bones. ${ }^{13-17}$ received

April 28, 2014

accepted after revision

March 10, 2015

published online

June 19, 2015 (c) 2016 Georg Thieme Verlag KG Stuttgart · New York
DOI http://dx.doi.org/ 10.1055/s-0035-1554808. ISSN 2193-6315. 
This report describes a case of primary GCT located in the temporal bone of the skull and reviews the relevant published literature in relation to diagnosis, treatment, and prognosis of this phenomenon. We conclude with suggestions concerning a treatment strategy for GCTs in the skull.

\section{Case Presentation}

A 41-year-old man presented with a 2-year history of headache and 1-year history of hypacusia. One week before, the headache in the temporal region and mandible became severe. He had a fever $\left(38.8^{\circ} \mathrm{C}\right)$, stiff neck, and positive Kernig sign. His past medical history included cholelithiasis, and his family history was unremarkable.

Laboratory testing showed a C-reactive protein of $8.45 \mathrm{mg} /$ $\mathrm{dL}$ and a white blood cell count of $9,300 / \mu \mathrm{L}$. Cerebrospinal fluid (CSF) examination showed 71.5 cells $/ \mu \mathrm{L}$ (mononuclear cell, $98 \%$; polynuclear cell, $2 \%$ ), a total protein of $98 \mathrm{mg} / \mathrm{dL}$, and a glucose of $56 \mathrm{mg} / \mathrm{dL}$. Xanthochromia was present. X-ray showed no neoplastic lesions on any of the epiphyses of the long bones. Head computed tomography (CT) showed a lytic expansive extradural lesion $5 \mathrm{~cm}$ in diameter originating primarily from the right temporal bone and expanding into the middle cranial fossa and the infratemporal fossa. The mass lesion had an inhomogeneous low density and had calcification in the peripheral zone (-Fig. 1A). This extradural lesion caused mass effect on the temporal cortex, and a low-density area was apparent in the temporal cortex. Contrast-enhanced CT revealed no areas of enhancement. Head magnetic resonance imaging (MRI) showed an extradural lesion that contained multilocular cysts. The periphery had a low intensity on T1-weighted imaging and in T2-weighted imaging and the center had a high intensity on T1-weighted imaging and T2weighted imaging. Cysts of the tumor did not enhance, but the attached dura enhanced markedly ( - Fig. 1B). The low-density area in the temporal cortex on CT corresponded with an area of high density of T1-weighted MR imaging (-Fig. 1C). Temporal bone target CT showed bony erosion of the middle cranial fossa and mandible and a mass lesion in the external auditory canal ( - Fig. 1D). Angiographic examination showed tumor stain from the right superficial temporal artery and the middle meningeal artery.

The patient was hospitalized, and meningitis was treated with a course of antibiotics. Biopsy of the lesion was obtained via the external auditory meatus under local anesthesia. Histologic examination showed findings consistent with
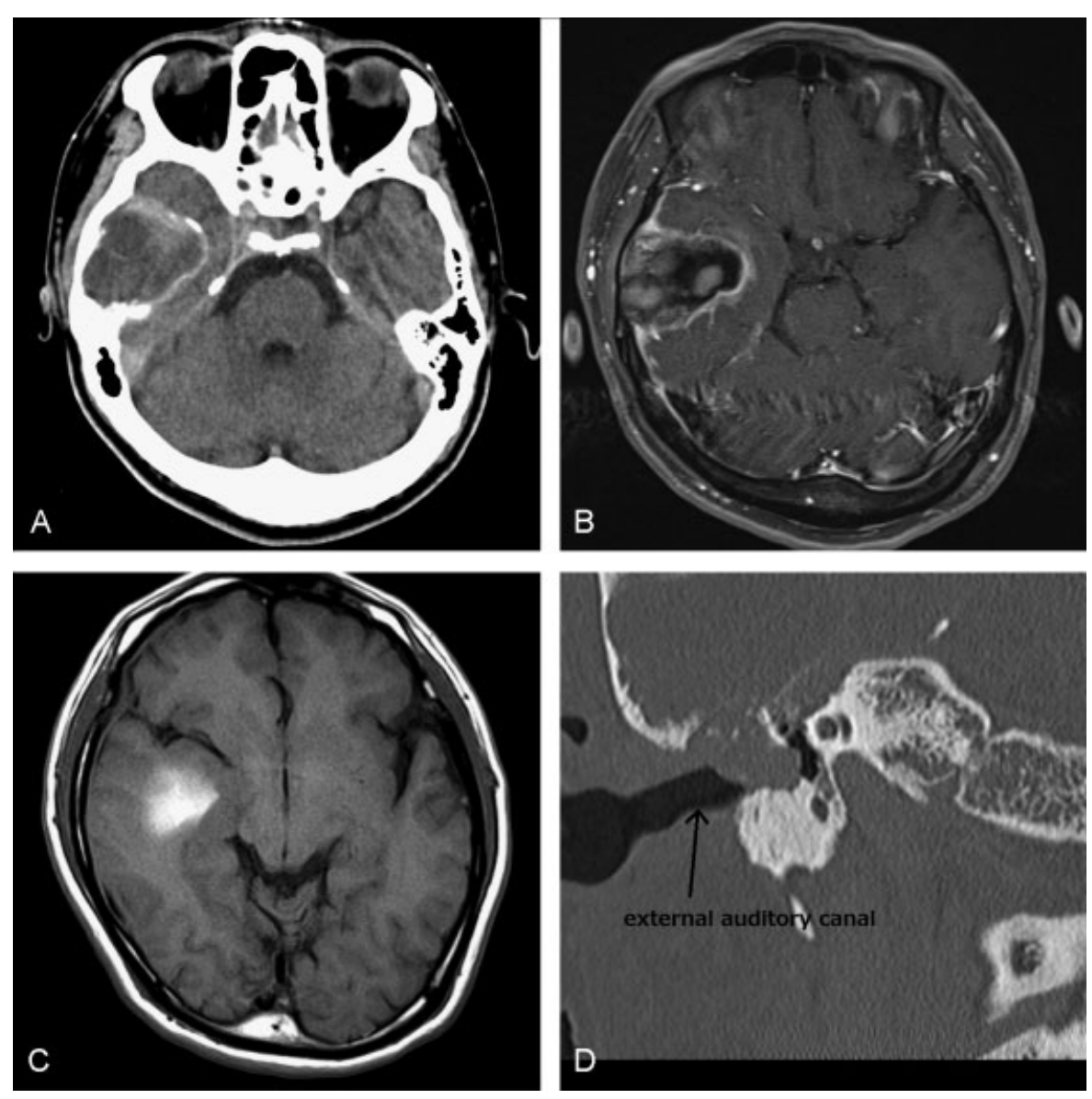

Fig. 1 (A) Axial plain computed tomography (CT) scan at the time of admission shows a lytic expansive extradural inhomogeneous mass $5 \mathrm{~cm}$ in diameter arising from the right temporal bone and compressing the temporal cortex. Calcification is present in the peripheral zone. (B) Axial enhanced magnetic resonance (MR) image shows an extradural lesion that contains multiple cysts without enhancement. The attached dura is well enhancing. (C) Axial plain T1-weighted MR image shows a high-intensity area in the right temporal cortex. (D) Target coronal CT scan of the right temporal bone shows an invaded base of the temporal fossa and a mass lesion extending toward the external auditory canal. 
bone tumor including GCT of bone. Neuronavigation-guided tumor removal was performed with temporal craniectomy, tympanoplasty, mastoidectomy, and removal of the mandibular condylar process and zygomatic arch. The tumor had invaded into the squamous part of the temporal bone and temporal muscle, and it had some cysts with a soft membrane and a blood component. The contents of the tumor had the appearance of yellow powder, and the tumor was hypovascular. The dura and arachnoid were yellowish and thickened. The brain parenchyma had an appearance similar to that seen in a crush wound. The foramen rotundum was normal, but the foramen ovale and spinosum were destroyed. The Fallopian canal was not eroded and the chorda tympani was not invaded; the tympanic membrane and ossicles (malleus and incus) were eroded but the stapes was intact. The tumor was resected totally along with the eroded dura,then tympanoplasty (type III+ replacement cartilage with conductance), and mastoidectomy were performed. The defect in the dura was covered with periosteum, and the zygomatic arch and temporal convexity were reconstructed using a titanium mesh plate (-Fig. 3D).

Histologic examination showed that this tumor was composed of mononuclear cells and osteoclast-like multinucleated giant cells ( - Fig. 2A), similar to the histologic findings of the biopsy specimen. The mononuclear cells resembled monocytes, and the nuclear atypia was mild to moderate. The nuclei of the multinucleated giant cells were similar to those of mononuclear cells. There was almost no mitotic figure. Areas of hemorrhage, hemosiderin deposition, necrosis, and fibrosis were seen, and multiple cystic changes were present. The cysts were filled with old blood and had a fibrous cyst wall without lining cells (-Fig. 2B). The tumor had

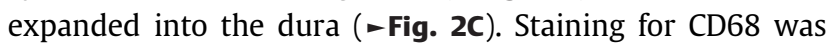
positive on both multinucleated giant cells and mononuclear cells. The MIB-1 index was $<5 \%$. Histopathologically, the tumor was diagnosed as GCT, and the cysts were considered to be secondary aneurysmal bone cysts.
Gross total resection of the tumor was achieved and confirmed by postoperative MRI ( - Fig. 3A, B). The mass effect and the high-intensity lesion in the temporal cortex disappeared (-Fig. 3C). The low-density area on CT in the temporal cortex also disappeared. Three-dimensional CT

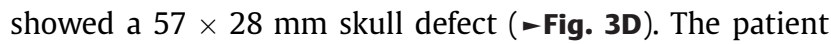
had no neurologic deficits after surgery. His chief complaint (headache) and his hearing loss resolved. At the 4-month follow-up, he has made satisfactory progress without recurrence.

\section{Discussion}

The present report described a case of GCT in the temporal bone and involving the zygomatic arch, temporal muscle, infratemporal fossa, ossicula auditus, and dura. GCT is a tumor that arises from connective tissue within bone marrow, and it usually involves the epiphysis of long bones. Although GCTs constitute $5 \%$ of all primary bone tumors, GCTs in the skull are very rare. Moreover, GCTs invading to the infratemporal fossa like our case was reported only in one case. ${ }^{18}$ We reviewed the published literature ( $\mathbf{- T a b l e ~} \mathbf{1})$.

\section{Symptoms}

Symptoms of GCTs vary according to the location of the tumor and associated nerve invasion, although headache is a common symptom regardless of tumor location. GCTs of the temporal bone are usually associated with pain behind the ear, conductive hearing loss resulting from the tumor invading the infratemporal fossa and obstructing the eustachian tube, and facial weakness. GCTs involving the sphenoid bone are associated with headache, ophthalmoparesis, trigeminal hypesthesia, and visual disturbance. GCTs in the sellar region are associated with headache, visual field defect, blindness, diplopia, dysfunction of the second through eighth cranial nerves, neck pain, endocrinopathy, and mental status changes. $^{2}$
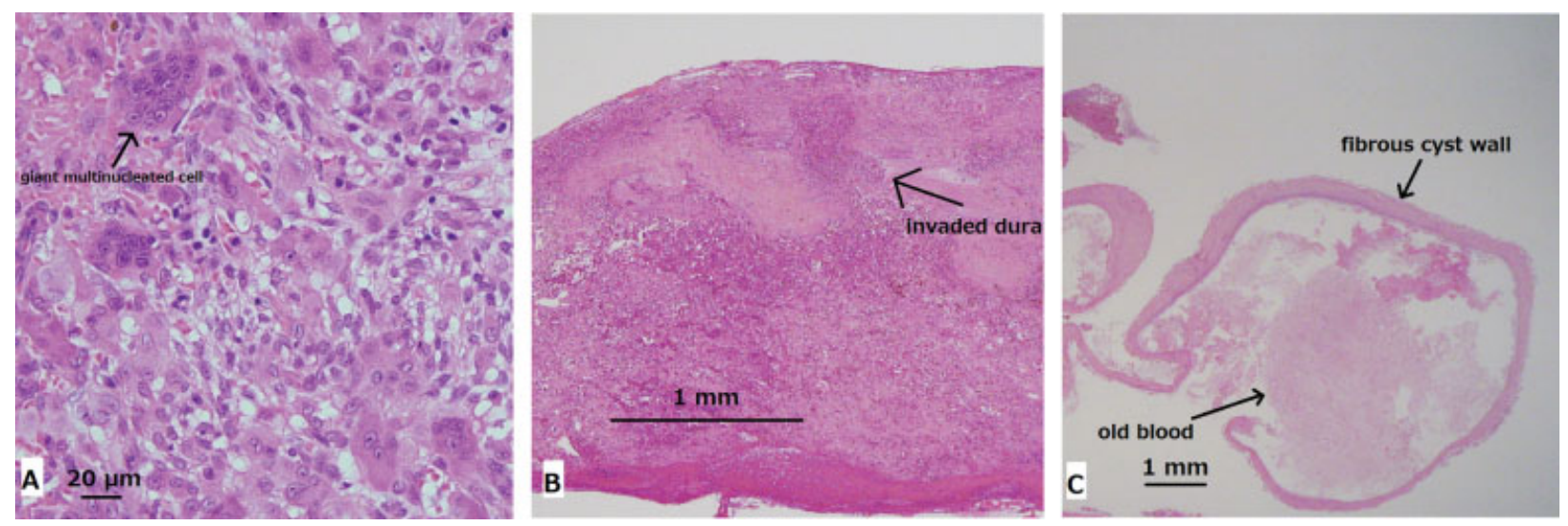

Fig. 2 (A) Photomicrograph showing a giant cell tumor section composed of mononuclear cells and scattered numerous giant multinucleated cells (hematoxylin and eosin [H\&E] original magnification $\times 400$; magnification bar: $20 \mu \mathrm{m}$ ). (B) Cross section of the vein with multinuclear giant cells in the dura (H\&E original magnification $\times 40$; magnification bar: $1 \mathrm{~mm}$ ). (C) Cysts contain blood constituents; the cyst wall is fibroid and shows hyaline degeneration. The cysts do not adhere to solid tissue, mainly because tumor cells around the cysts underwent necrosis (H\&E original magnification $\times 12.5$; magnification bar: $1 \mathrm{~mm}$ ). 

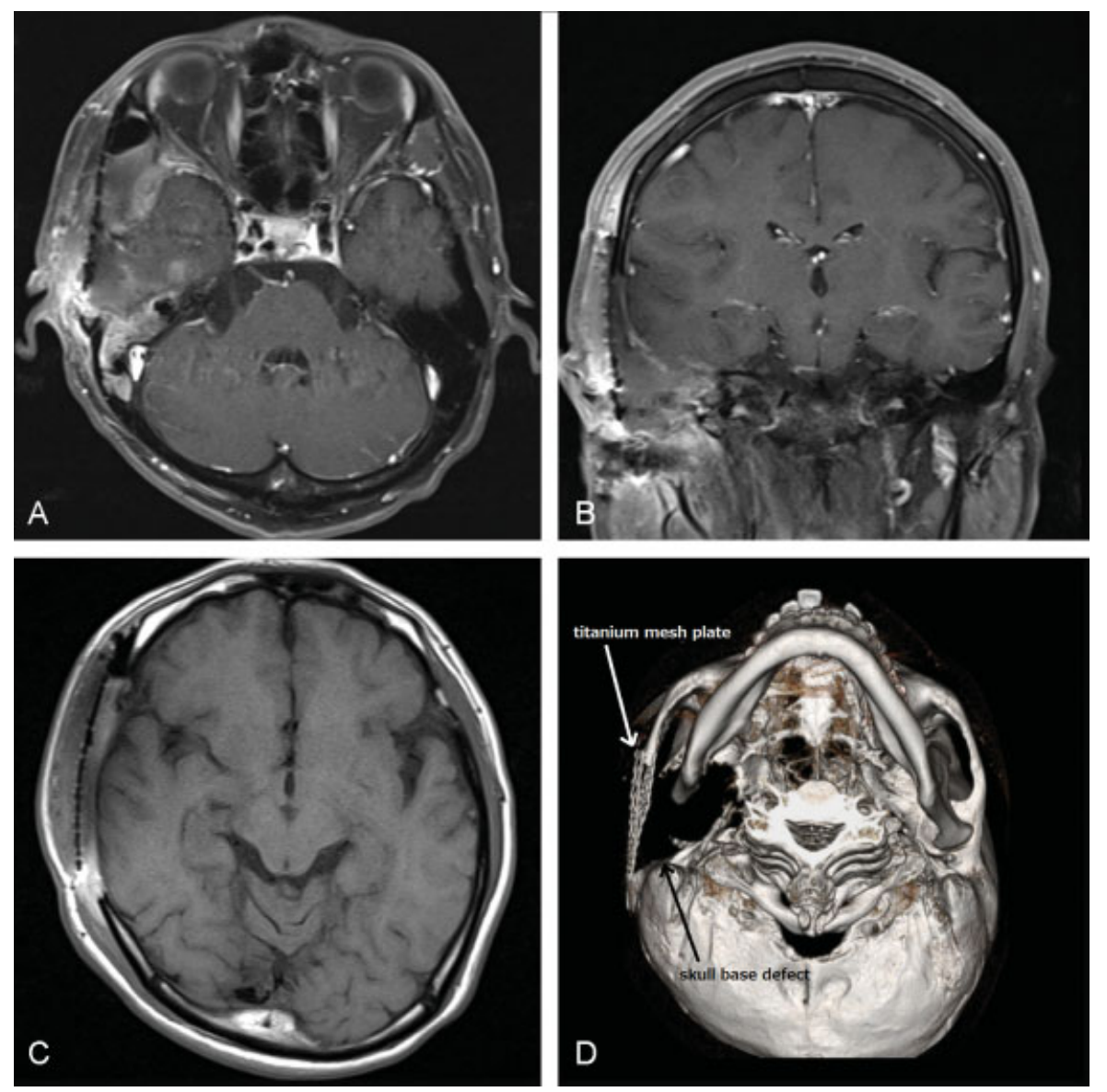

Fig. 3 (A) Axial enhanced T1-weighted magnetic resonance (MR) image after operation shows total removal of tumor and resolution of compression of the temporal cortex. (B) Coronal enhanced T1-weighted MR image after surgery shows the defect in the temporal skull base. (C) Axial plain T1-weighted MR image after operation shows disappearance of high-intensity area in the right temporal cortex. (D) Bone threedimensional computed tomography scan shows a $57 \times 28-\mathrm{mm}$ temporal skull base defect and the removal of the processus condylaris. The temporal convexity and zygomatic arch are reconstructed using a titanium mesh plate.

In the present case, there was no apparent increases of polynucleate cells, but meningitis was suspected prior to surgery by the clinical appearance of stiff neck, headache, and fever. Chemical meningitis caused by the leak of the tumor component into the CSF is one possibility. A bacterial meningitis was considered to be unlikely, but if it would have been the case, a relation to the external auditory meatus or mastoid air cells could have been assumed.

There have been no reports of GCTs with meningitis in the published literature.

\section{Histopathologic Data}

GCTs of the temporal bone sometimes invade into the external auditory meatus. This allowed us to perform a preoperative biopsy using a fiberscope via the external auditory meatus. GCTs of the sphenoid bone are sometimes amenable to biopsy via the nasal cavity.

Osteoclast-like giant cells and their precursors express receptor activator of nuclear factor $\mathrm{k}-\beta$ (RANK), and some mononuclear cells and stromal cells express RANK ligand (RANKL). RANKL has three isoforms and is usually produced as the membrane-bound type (RANKL 1). RANKL 2 has a shorter intracellular domain than the RANKL 1, and RANKL 3 lacks a transmembrane domain and is produced from RANKL 1 via cleavage by metalloprotease. RANKL 3 is thought to act as a soluble form of RANKL (sRANKL). ${ }^{19,20}$ It is said that the aggressive osteolytic activity of GCTs is related to RANKL 1 and 3. Thus RANKL 1 and 3 may represent therapeutic targets for the management of GCTs of the long bones. ${ }^{15}$

\section{Differential Diagnosis}

GCT is difficult to distinguish from giant cell reparative granuloma (GCRG) because these two lesions have a similar radiographic appearance. GCTs generally have larger giant cells and more nuclei when compared with GCRGs. Further, giant cells are found diffusely throughout the tissue in GCTs and tend to be localized in hemorrhagic sites in GCRGs. Bone cortex is destroyed in GCTs and maintained in GCRGs. GCTs tend to have a stronger degree of nuclear atypia and a greater number of mitosis when compared with GCRGs.

In the present patient, giant cells were seen diffusely throughout the tissue specimen (including the biopsy specimen obtained via the external auditory meatus) with a locally aggressive appearance. Also, the specimen had a mild degree of nuclear atypia and few mitoses. While the specimen showed necrosis, it was difficult to differentiate 


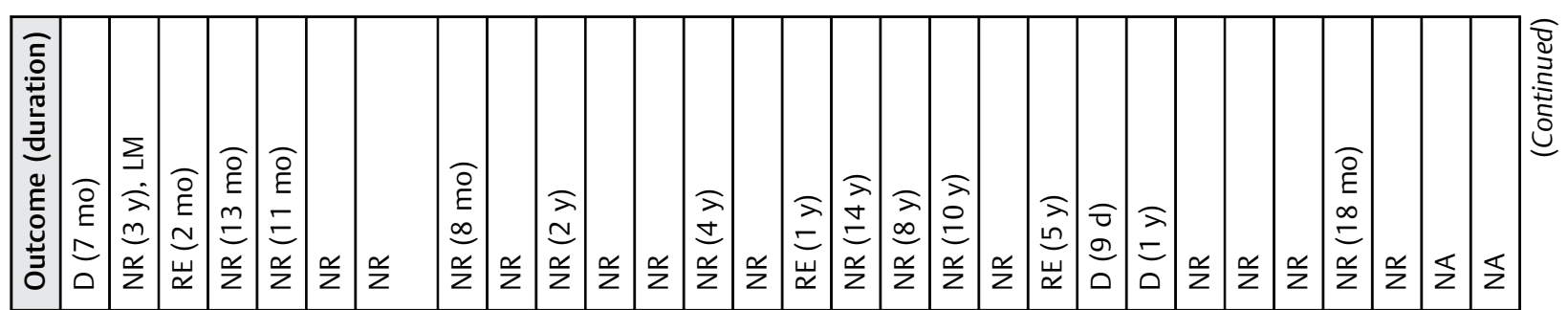

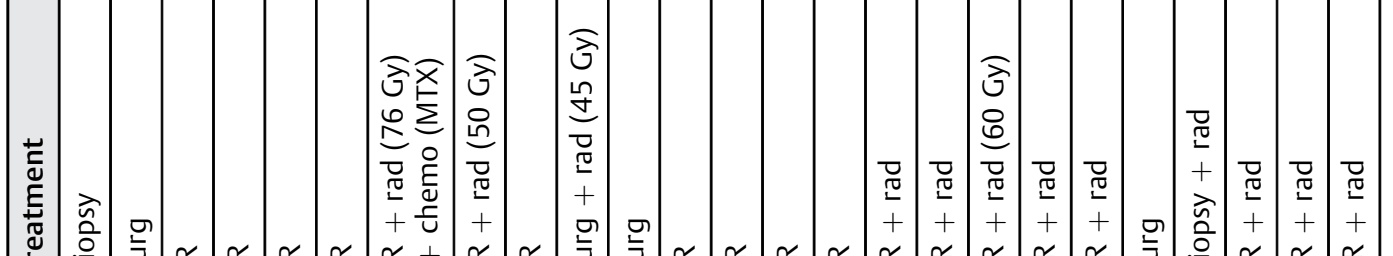

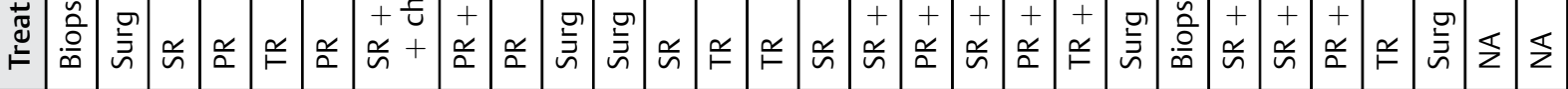

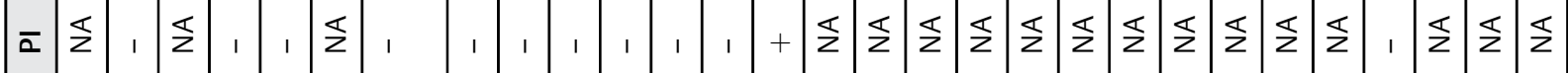

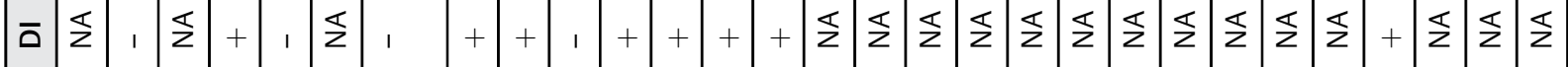

E

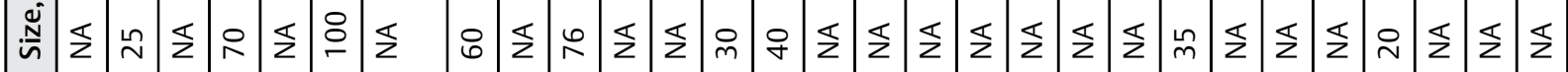

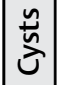

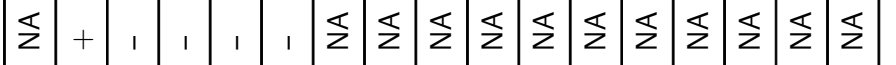

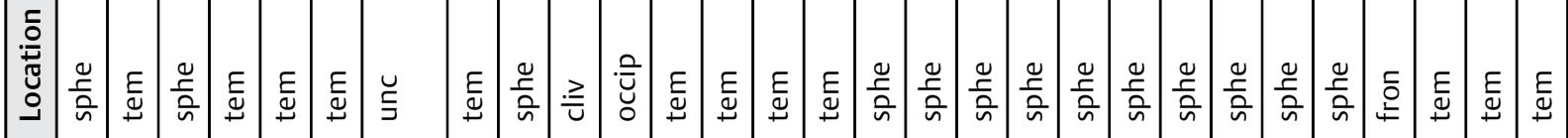

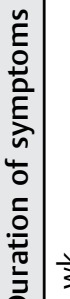

气

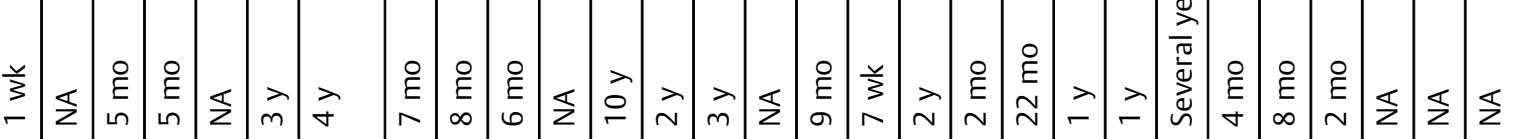

ॐ

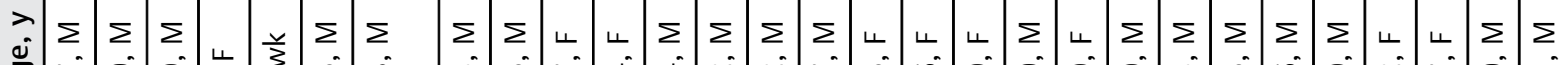

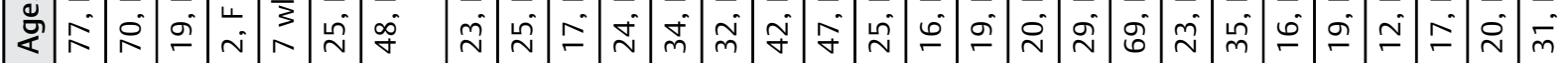

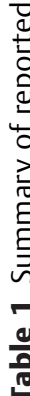

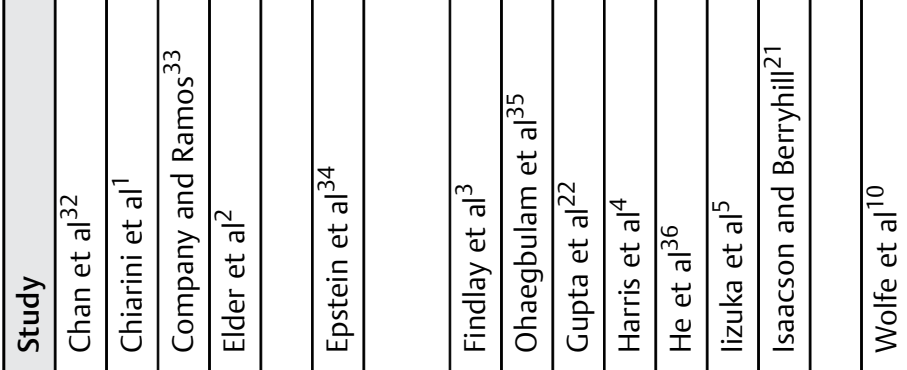

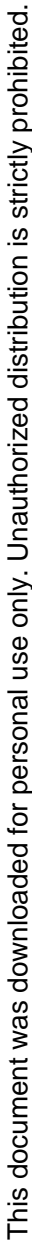




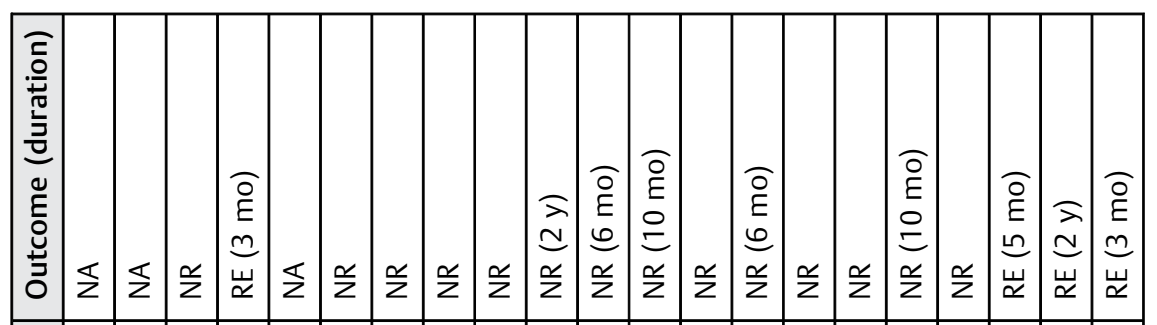

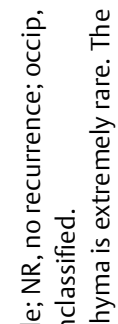

\begin{tabular}{|c|c|c|c|c|c|c|c|c|c|c|c|c|c|c|c|c|c|c|}
\hline $\overrightarrow{\underline{\Xi}}$ & $\Sigma$ & $\Sigma$ & $\stackrel{\alpha}{\vdash}$ & $\begin{array}{l}\text { 苋 } \\
+ \\
\text { o } \\
\stackrel{亏}{n}\end{array}$ & $\stackrel{\sim}{\sim}$ & $\stackrel{\sim}{\sim}$ & 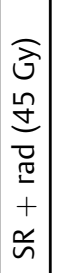 & 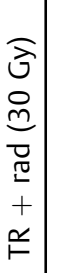 & & 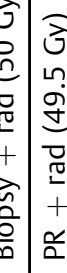 & 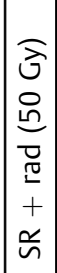 & $\stackrel{\sim}{F}$ & $\stackrel{\sim}{F}$ & 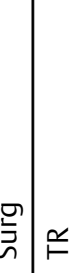 & $\stackrel{\sim}{\sim}$ & 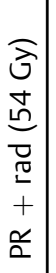 & 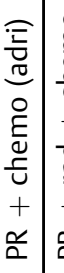 & 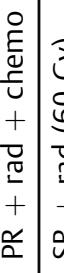 \\
\hline $\bar{a}$ & $\Sigma$ & $\Sigma$ & 1 & 1 & 1 & 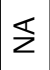 & 1 & 1 & 1 & 1 & 1 & 1 & 1 & $1 \sum$ & + & 1 & $\Sigma$ & 1 \\
\hline & & & & & & $\Sigma$ & 1 & & 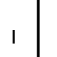 & । & & & । & । & + & & $\Sigma$ & \\
\hline
\end{tabular}

E

ที่

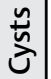

$\varangle \leftleftarrows$

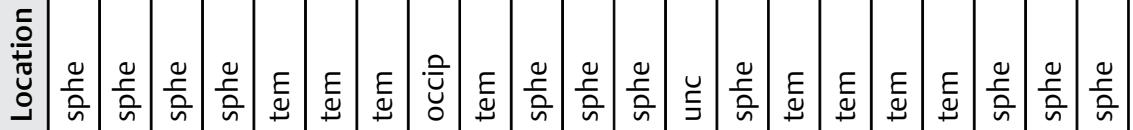

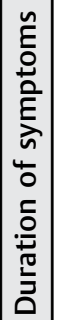

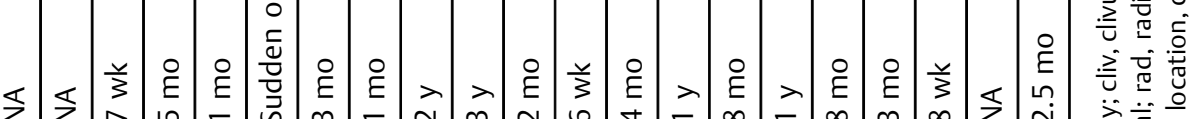

๖

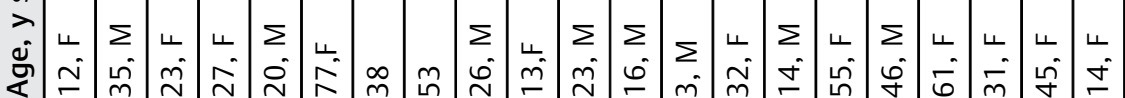

高苛

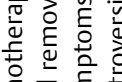

产

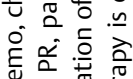

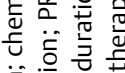

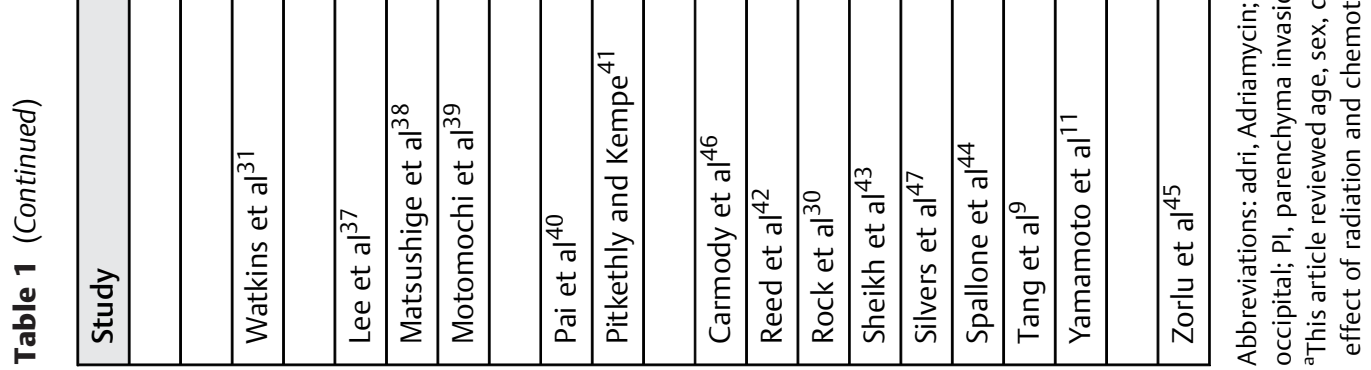


between primary necrosis due to tumor itself and secondary necrosis.

Paget disease of the bone is sometimes complicated by GCT. It usually shows a high level of alkaline phosphatase, increase in the density of the bone, formation of bone trabeculae, thickened cortical bone, and sclerosis that is said to have a cotton wool like appearance in X-ray. Histopathologically, Paget disease shows a mosaic pattern with mixed sclerosis and absorption. Basically, GCT caused by Paget disease originates in the metaphyseal region of long bones, skull, facial bone (especially bones of the jaw), and spine. If GCT is located in the bones of the jaw, Paget disease must be considered. ${ }^{21}$ The present case did not have these characteristics.

Aneurysmal bone cysts are benign lesion composed of large vascular spaces separated by trabeculae of connective tissue and bone. GCT is sometimes complicated by secondary aneurysmal bone cysts, so it is important to distinguish between GCT and primary aneurysmal bone cysts. Radiographically, GCT also involves the epiphysis, which is in contrast with aneurysmal bone cysts that usually originate in the diaphysis. Histopathologically, if tumor components are seen, it is not a primary aneurysmal bone cyst. ${ }^{21}$ In the present case secondary aneurysmal bone cysts were seen.

\section{Treatment}

Although GCTs in the skull are locally aggressive, a malignant phenotype exists in only 5 to $10 \%$ of cases. Patients who may benefit from chemotherapy are either those with GCTs that are incompletely resectable or those with GCTs that are not suitable for surgery. No standard chemotherapy protocol exists for the treatment of GCTs. ${ }^{11}$ Patients have been treated with interferon- $\alpha$ and chemotherapeutic regimens consisting of methotrexate, cyclophosphamide, and doxorubicin with limited success. Some reports have described the use of radiation therapy alone or after surgery for patients with GCTs. ${ }^{3,9,11,22}$ However, radiation may cause a sarcomatous transformation in the residual tumor tissue. Other authors believe that GCTs are not radiosensitive. ${ }^{2,6,11}$ Recent reports suggest that RANKL 1 and 3 are targets of treatment for GCTs of the long bone. ${ }^{15,16}$ Denosumab is a fully human monoclonal antibody that specifically inhibits membrane-bound and soluble RANKL, thereby inhibiting osteoclast-like giant cellmediated bone destruction. One article showed that denosumab was effective in $86 \%$ of the patients who had unresectable and recurrent GCTs of the long bones. ${ }^{15}$ The histopathologic characteristics of GCT in the skull are similar to GCT of the long bones. In the same way, we believe that denosumab might inhibit bone destruction and eliminate giant cells in the skull. However, denosumab is not currently approved for use in Japan.

In the present case, the concentration of sRANKL in the serum was $18.5 \mathrm{ng} / \mathrm{mL}$ (296 $\mathrm{pmol} / \mathrm{L})$, which is higher than that seen in control patients $(62 \pm 43 \mathrm{pg} / \mathrm{mL}){ }^{23-26}$ Possibly, sRANKL can be useful detecting recurrence at an early stage because some previous reports showed that the aggressive osteolytic activity of GCTs are related to RANKL $3 .{ }^{15}$ The level of sRANKL can be easily monitored through sampling of peripheral blood. ${ }^{27}$

Antiosteoclastic agents such as bisphosphonates have the same effect as denosumab. Bisphosphonates can be used to mitigate bone destruction and prevent local recurrence following surgery in patients with osteolytic neoplasms, such as GCTs of the long bones. ${ }^{13,15-17,28,29}$ One study suggested that postoperative treatment of patients with GCTs in the long bones with oral bisphosphonate produce symptomatic benefit and decrease recurrence rates, even though no change in tumor size was observed with preoperative treatment. ${ }^{16}$ So we utilized an oral bisphosphonate for our patient after discharge to prevent recurrence.

\section{Prognosis}

GCTs in the skull have a low potential for metastasis, but they are locally aggressive and accompanied by a high rate of recurrence (40-60\%). ${ }^{27,30}$ Therefore they are not strictly clinically benign. In our review, the recurrence rate was $22 \%$. Preoperative diagnosis by biopsy is thus very important to help guide whether complete resection should be performed or not because the risk of recurrence is related to the degree of resection rather than to the degree of invasiveness. The risk of relapse also varies according to the location of GCTs. For example, the GCTs of the sphenoid bone cannot be resected completely because the cavernous sinus is often involved. By contrast, GCTs of the temporal bone are relatively easy to resect. ${ }^{31}$

A few reports describe the relationship between the removal and recurrence rate. Only 1 of 11 patients with total removal had a recurrence, whereas 5 of 11 patients with subtotal removal experienced recurrence. In our review, the maximum time to recurrence was 60 months (average: 15 months). Close follow-up is necessary for at least a period of 60 months, especially during the first year after surgery.

Our review of the published literature showed that 3 of 50 patients died. One such case was related to sepsis and a cerebrovascular accident. ${ }^{3}$ The other cases of death were related to multifocal gastroduodenal ulceration and tumor growth. ${ }^{10}$

\section{Conclusions}

Preoperative diagnosis by biopsy is critical to help guiding the therapy. Complete resection of the tumor is important to reduce the risk of recurrence. It is often difficult to remove the tumor totally in some locations such as the sphenoid bone; therefore bisphosphonates may be useful in patients with recurrent or unresectable GCTs.

\section{References}

1 Chiarini L, Figurelli S, Ghidini A, et al. An unusual case of giant cell tumour involving the middle cranial fossa, originating from soft tissues of the temporomandibular joint. Acta Neurochir (Wien) 2009;151(12):1685-1687

2 Elder JB, Berry C, Gonzalez-Gomez I, Kreger MD, McComb JG. Giant cell tumor of the skull in pediatric patients. Report of two cases. J Neurosurg 2007;107(1, Suppl):69-74 
3 Findlay JM, Chiasson D, Hudson AR, Chui M. Giant-cell tumor of the middle cranial fossa. Case report. J Neurosurg 1987;66(6): 924-928

4 Harris AE, Beckner ME, Barnes L, Kassam A, Horowitz M. Giant cell tumor of the skull: a case report and review of the literature. Surg Neurol 2004;61(3):274-277

5 Iizuka T, Furukawa M, Ishii H, et al. Giant cell tumor of the temporal bone with direct invasion into the middle ear and skull base: a case report. Case Rep Otolaryngol 2012;2012:690148

6 Kamoshima Y, Sawamura Y, Imai T, Furukawa H, Kubota K, Houkin K. Giant cell tumor of the frontal bone in a girl: case report. Neurol Med Chir (Tokyo) 2011;51(11):798-800

7 Kashiwagi N, Hirabuki N, Andou K, et al. MRI and CT findings of the giant cell tumors of the skull; five cases and a review of the literature. Eur J Radiol 2006;58(3):435-443

8 Park Y-S, Lee JK, Baek S-W, Park CK. The rare case of giant cell tumor occuring in the axial skeleton after 15 years of follow-up: case report. Oncol Lett 2011;2(6):1323-1326

9 Tang J-Y, Wang C-K, Su Y-C, Yang SF, Huang MY, Huang CJ. MRI appearance of giant cell tumor of the lateral skull base: a case report. Clin Imaging 2003;27(1):27-30

10 Wolfe JT III, Scheithauer BW, Dahlin DC. Giant-cell tumor of the sphenoid bone. Review of 10 cases. J Neurosurg 1983;59(2):322-327

11 Yamamoto M, Fukushima T, Sakamoto S, Tomonaga M. Giant cell tumor of the sphenoid bone: long-term follow-up of two cases after chemotherapy. Surg Neurol 1998;49(5):547-552

12 Echols DH. Giant cell tumor of the sphenoid bone- report of a case. J Neurosurg 1945;2:16-20

13 Balke M, Campanacci L, Gebert C, et al. Bisphosphonate treatment of aggressive primary, recurrent and metastatic giant cell tumour of bone. BMC Cancer 2010;10:462

14 Chaudhary P, Khadim H, Gajra A, Damron T, Shah C. Bisphosphonate therapy is effective in the treatment of sacral giant cell tumor. Onkologie 2011;34(12):702-704

15 Thomas D, Henshaw R, Skubitz K, et al. Denosumab in patients with giant-cell tumour of bone: an open-label, phase 2 study. Lancet Oncol 2010;11(3):275-280

16 Thomas DM. RANKL, denosumab, and giant cell tumor of bone. Curr Opin Oncol 2012;24(4):397-403

17 Tse LF, Wong KC, Kumta SM, Huang L, Chow TC, Griffith JF. Bisphosphonates reduce local recurrence in extremity giant cell tumor of bone: a case-control study. Bone 2008;42(1): 68-73

18 Roberts DS, Faquin WC, Deschler DG. Giant cell tumors of the temporal bone and infratemporal fossa: a case report and review of the literature. Laryngoscope 2010;120(Suppl 4):S180

19 Buckle CH, De Leenheer E, Lawson MA, et al. Soluble rank ligand produced by myeloma cells causes generalised bone loss in multiple myeloma. PLoS ONE 2012;7(8):e41127

20 Ikeda T, Kasai M, Utsuyama M, Hirokawa K. Determination of three isoforms of the receptor activator of nuclear factor-kappaB ligand and their differential expression in bone and thymus. Endocrinology 2001;142(4):1419-1426

21 Isaacson B, Berryhill W, Arts HA. Giant-cell tumors of the temporal bone: management strategies. Skull Base 2009; 19(4):291-301

22 Gupta R, Mohindra S, Mahore A, Mathuriya SN, Radotra BD. Giant cell tumour of the clivus. Br J Neurosurg 2008;22(3):447-449

23 Doumouchtsis K, Perrea D, Doumouchtsis S, et al. Regulatory effect of parathyroid hormone on SRANKL-osteoprotegerin in hemodialysis patients with renal bone disease. Ther Apher Dial 2009; 13(1):49-55

24 Dovio A, Generali D, Tampellini M, et al. Variations along the 24hour cycle of circulating osteoprotegerin and soluble RANKL: a rhythmometric analysis. Osteoporos Int 2008;19(1):113-117
25 Jung K, Lein M, Hösslin Kv, et al. Osteoprotegerin and receptor activator of nuclear factor-kappaB ligand (RANKL) in the serum of healthy adults. Int J Biol Markers 2002;17(3):177-181

26 Ohwada R, Hotta M, Sato K, Shibasaki T, Takano K. The relationship between serum levels of estradiol and osteoprotegerin in patients with anorexia nervosa. Endocr J 2007;54(6):953-959

27 Zhu LL, Bao NR, Zhou LW, Guo T, Zeng XF, Zhao JN. Concentration measurement of the OPG and sRANKL of peripheral blood among normal healthy people [in Chinese]. Zhongguo Gu Shang 2010; 23(2):87-89

28 Henry DH, Costa L, Goldwasser F, et al. Randomized, double-blind study of denosumab versus zoledronic acid in the treatment of bone metastases in patients with advanced cancer (excluding breast and prostate cancer) or multiple myeloma. J Clin Oncol 2011;29(9):1125-1132

29 Lipton A, Fizazi K, Stopeck AT, et al. Superiority of denosumab to zoledronic acid for prevention of skeletal-related events: a combined analysis of 3 pivotal, randomised, phase 3 trials. Eur J Cancer 2012;48(16):3082-3092

30 Rock JP, Mahmood A, Cramer HB. Giant cell tumor of the skull base. Am J Otol 1994;15(2):149-152

31 Watkins LD, Uttley D, Archer DJ, Wilkins P, Plowman N. Giant cell tumors of the sphenoid bone. Neurosurgery 1992;30(4):576-581

32 Chan J, Gannon FH, Thompson LDR. Malignant giant cell tumor of the sphenoid. Ann Diagn Pathol 2003;7(2):100-105

33 Company MM, Ramos R. Giant cell tumor of the sphenoid. Arch Neurol 2009;66(1):134-135

34 Epstein N, Whelan M, Reed D, Aleksic S. Giant cell tumor of the skull: a report of two cases. Neurosurgery 1982;11(2):263-267

35 Ohaegbulam SC, Indu M. Gupta. Giant cell tumour of the sphenoid bone with dural extension. J Neurol Neurosurg Psychiatry 1977; 40(8):790-794

36 He D, Yang C, Shen G, et al. Navigation-guided resection for a tenosynovial giant cell tumor involving the temporomandibular joint and skull base. J Craniofac Surg 2012;23(2):521-523

37 Lee JA, Bank WO, Gonzalez-Melendez M, Olan WJ, Tabbara SO. Giant cell tumor of the skull. Radiographics 1998;18(5): 1295-1302

38 Matsushige T, Nakaoka M, Yahara K, et al. Giant cell tumor of the temporal bone with intratumoral hemorrhage. J Clin Neurosci 2008;15(8):923-927

39 Motomochi M, Handa Y, Makita Y, Hashi K. Giant cell tumor of the skull. Surg Neurol 1985;23(1):25-30

40 Pai SB, Lalitha RM, Prasad K, Rao SG, Harish K. Giant cell tumor of the temporal bone-a case report. BMC Ear Nose Throat Disord 2005;5:8

41 Pitkethly DT, Kempe LG. Giant cell tumors of the sphenoid. Report of two cases. J Neurosurg 1969;30(3):301-304

42 Reed L, Willison CD, Schochet SS Jr, Voelker JL. Giant cell tumor of the calvaria in a child. Case report. J Neurosurg 1994;80(1): 148-151

43 Sheikh M, Chisti FA, Sinan T. Giant cell tumour of the temporal bone: case report and review of the literature. Australas Radiol 1999;43(1):113-115

44 Spallone A, Flores GL, Zaldivar LO, Estupinan B. Giant cell tumor (osteoclastoma) of the petrous bone: case report. Skull Base Surg 1999;9(2):155-159

45 Zorlu F, Selek U, Soylemezoglu F, Oge K. Malignant giant cell tumor of the skull base originating from clivus and sphenoid bone. J Neurooncol 2006;76(2):149-152

46 Carmody RF, Rickles DJ, Johnson SF. Giant cell tumor of the sphenoid bone. J Comput Assist Tomogr 1983;7(2):370-373

47 Silvers AR, Som PM, Brandwein M, Chong JL, Shah D. The role of imaging in the diagnosis of giant cell tumor of the skull base. AJNR Am J Neuroradiol 1996;17(7):1392-1395 